\title{
ETHICS, LAW, AND MEDICINE
}

\section{The criminalisation of HIV transmission}

\section{J Chalmers}

Correspondence to: Mr J Chalmers, School of Law, University of Aberdeen, Taylor Building, Old Aberdeen AB24 3UB; i.p.chalmers@abdn.ac.uk.

Revised version received 24 January 2002 Accepted for publication 30 January 2002
Since Bennett, Draper, and Frith published a paper in the Journal of Medical Ethics in 2000 considering the possible criminalisation of HIV transmission, an important legal development has taken place. February 2001 saw the first successful United Kingdom prosecution for the sexual transmission of disease for over a century, when Stephen Kelly was convicted in Glasgow of recklessly injuring his former girlfriend by infecting her with HIV. Whether English criminal law (as opposed to Scots law) can apply criminal penalties in such a case, however, still remains uncertain.

This paper, in addition to providing some background to the Kelly case, briefly explores the current possibilities for prosecution under English law. It then proceeds to outline and comment on the issues relevant to criminalisation, responding in part to points made by Bennett, Draper, and Frith and also by Bird and Leigh Brown in a recent article in the BM. n 2000, Bennett, Draper, and Frith published a paper in the Journal of Medical Ethics considering the question of whether an HIV-positive individual could be said to have a moral duty to inform sexual partners of their HIV-positive status, and whether this moral duty should be reinforced by the criminal law. ${ }^{1}$ Since that paper appeared, an important legal development has taken place. In February 2001, at the High Court in Glasgow, Stephen Kelly became the first ever person to be convicted in the UK of transmitting HIV-and, indeed, the first person to be successfully prosecuted for the sexual transmission of disease for over a century.

Stephen Kelly was a 33 year old man who had become HIVpositive as a result of intravenous drug use while he was serving a prison sentence. He had tested positive for HIV whilst in prison and had received harm reduction counselling from a nurse in the prison. Some time after being released from prison, he commenced a sexual relationship with a woman called Anne Craig, to whom he did not disclose his HIV-positive status-and, indeed, told her that it was unnecessary for them to use condoms. Anne Craig subsequently tested HIV-positive. At the High Court of Justiciary in Glasgow, in February 2001, Stephen Kelly was convicted of the offence of recklessly causing injury to another, and was subsequently sentenced to five years imprisonment.

Scotland and England have different systems of criminal law, and Kelly's conviction is no guarantee that a similar prosecution would succeed in England. No written judgment was issued in the Kelly case, and the potential scope of Scots criminal law in this area remains unresolved. These issues are explored elsewhere, ${ }^{2}$ and this paper will focus primarily on English law, which is likely to be of more interest to the current readership.

\section{WHERE DOES ENGLISH LAW STAND?}

Bennett, Draper, and Frith make reference on a number of occasions to Law Commission proposals which would, if enacted, create specific offences relating to the transmission of disease. Such offences would clearly cover cases of HIV transmission. Discussion of these is at present purely academic, however, as it is clear that the government has no intention of bringing forward such legislation. In a 1998 Home Office consultation paper, the government proposed that "the criminal law should apply only to those whom it can be proved beyond reasonable doubt had deliberately transmitted a disease intending to cause a serious illness". ${ }^{3}$
If the government legislates at all in this area, it is likely to produce legislation in line with the 1998 proposals rather than the earlier Law Commission suggestions. An offence such as the one suggested would, in practice, have a considerably limited scope. Cases where the prosecution can prove beyond reasonable doubt that (a) transmission of HIV has taken place; (b) the defendant was the source of the complainant's infection, and (c) the defendant intended that such transmission take place (and was not simply reckless as to the possibility) are likely to be rare indeed.

At present, in the absence of legislation, the more important question is whether existing offences can be applied to the transmission of HIV. In the 1860s, English courts twice convicted men of indecent assault where they had induced women to have sexual intercourse with them in ignorance of the fact that they were carrying a venereal disease. ${ }^{4}$ In the leading case of Clarence, in 1888, however, the Queen's Bench Division held that these cases were wrongly decided. Consent to sexual intercourse was not to be regarded as invalid because of the failure to disclose a venereal disease. (Indeed, if it were, the accused would be guilty of rape, not simply indecent assault, which would seem inappropriate.)

Nor could there be a conviction for the offence of "unlawfully and maliciously inflicting grievous bodily harm", because "infliction" was to be regarded as referring to "the direct causing of some grievous injury to the body itself with a weapon, as by a cut with a knife, or without a weapon as by a blow with the fist, or pushing a person down". ${ }^{6}$ In other words, "infliction" requires a violent act. It is questionable, however, whether this view is still tenable. In 1997, the House of Lords recognised that a person might be guilty of inflicting grievous bodily harm by a series of silent telephone calls causing psychological damage, which would seem to refute this view by (arguably) equating "infliction" with "cause". ${ }^{7}$ This reopens the possibility of a person who transmits HIV to his or her sexual partner being prosecuted for this offence, and it has been claimed that, in light of the verdict in the Kelly case, the Crown Prosecution Service is re-examining a decision not to prosecute in at least one similar English case. ${ }^{8}$

It is clear that the UK has lagged behind other Englishspeaking countries in its approach to the transmission of HIV and the criminal law. Many US and Australian states have

Reproduced in full with permission from $\mathrm{J}$ Med Ethics 2002;28:160-163. 
enacted specific legislation criminalising HIV transmission in certain circumstances, while the Canadian courts have applied existing criminal offences in a series of judicial decisions. It will probably be impossible for policy-makers in the UK to avoid or ignore the issue of criminalisation indefinitely, although the matter may well be left in the hands of the courts, applying existing criminal offences, for some time yet. Bennett, Draper, and Frith's paper highlights some of the issues which will have to be considered. What follows is a discussion of how these issues might ideally be addressed rather than a description of how English law currently stands.

\section{LIMITATION TO HIV}

Bennett, Draper, and Frith argue that "the criminalisation of transmission of HIV alone is unjustifiable", and that criminal sanctions (if they are to be applied) should also apply to the transmission of "any communicable disease which leads to death or serious injury". That is surely correct, and it is in line with UN guidelines which recommend that it would be wrong to "single out" HIV in this fashion. ' It must be observed, however, that the seriousness of HIV is such that prosecutions for the transmission of any other disease would probably be rare. Indeed, the Canadian Criminal Code did formerly include an specific offence of knowingly transmitting a venereal disease, but this provision was repealed in 1985, just four years before the first Canadian prosecution for the transmission of $\mathrm{HIV}^{10}$ in large part because there had been no prosecution for the offence since 1922. ${ }^{11}$

That said, one can easily envisage cases where prosecutions might be brought in respect of other diseases. An attempt to prosecute a case of Hepatitis B transmission in 1998 failed because of the Clarence principle, ${ }^{12}$ while a prosecution for transmission of viral herpes appears to be ongoing at the time of writing. ${ }^{13}$

\section{TRANSMISSION OR EXPOSURE?}

One interesting facet of the position taken by Bennett, Draper, and Frith is that their analysis is concerned only with the criminalisation of HIV transmission. On their analysis, there should be no question of criminal liability unless the complainant has been "harmed by HIV infection".

It is far from clear, however, that this is the correct approach. If the moral wrong with which we are concerned lies in the failure to notify a sexual partner of one's HIV-positive status (as Bennett, Draper, and Frith have argued), then that wrong has been completed prior to the point at which HIV is transmitted (if, in fact, it is transmitted at all). If that is the case, it seems rather odd that the non-discloser's criminal liability should depend on the chance occurrence of whether HIV is transmitted (although that is not necessarily to say that we should not regard a case of transmission as more serious). ${ }^{14}$

To criminalise only causing harm (transmission) but not endangerment (exposure) appears, in principle, to accord chance an unduly prominent role in the attribution of criminal responsibility. ${ }^{15}$ That, in itself, is not a conclusive argument against criminalising only causing harm, for two reasons. First, it is wrong to say that outcomes are only ever a matter of luck, for we do control them to a greater or lesser extent. ${ }^{16}$ Second, we "should have only as much criminal law as we have to have", ${ }^{17}$ and it is generally felt unnecessary for the criminal law to extend as far in criminalising endangerment as it does in criminalising causing harm.

In the case of HIV exposure, however, the level of control exercised by the non-discloser over the possibility of transmission (assuming that unprotected vaginal or anal intercourse has taken place) is so minimal (if not nonexistent) that it seems proper to treat transmission as a matter of "luck", at least in so far as his own culpability is concerned.
To deal with the second point, although an overexpansive criminal law is to be avoided, limiting the offence to transmission would inevitably pose serious practical problems. It may not be possible to tell for some time if the complainant has in fact become HIV-positive as a result of the intercourse. Even if the complainant does test positive for HIV, it may not be possible to prove conclusively that the defendant was the source of the infection. Both the moral and practical arguments point towards the conclusion that, if the criminal sanction is to be applied in this area, it should apply both to transmission and exposure-a view which, it may be noted, has the support of the Canadian Supreme Court. ${ }^{18}$

This view would probably entail the creation of two separate offences-an offence of transmission and a distinct offence of exposure, rather than simply a general offence of exposure. One might ask, therefore, whether it would not be preferable simply to create a single offence of transmission and allow the possibility of prosecutions for "attempted transmission" in appropriate cases. The answer is that, while English law generally recognises attempts to commit indictable offences as themselves criminal, this is only the case where the person has acted with the intention of committing the full offence. ${ }^{19}$ While that would be an appropriate solution if one wished to restrict the culpability requirement for the offence to an intention to transmit the disease, a separate offence would be required in order to criminalise reckless exposure.

\section{KNOWLEDGE, RECKLESSNESS, AND DETERRING TESTING}

Bennett, Draper, and Frith not only require the complainant to have been "harmed" by HIV infection; he or she must also have been "wronged by not being forewarned of her partner's known HIV-positive status" (my italics). This requirement of express knowledge is introduced into the analysis without discussion or justification, and it is by no means self evident. It runs the risk, moreover, of encouraging persons who suspect they might be HIV-positive to refrain from taking an HIV test in the hope that this will protect them from the sanction of the criminal law. English law does, in certain cases, treat "wilful blindness" as equivalent to knowledge, ${ }^{20}$ although this might be felt to be (from the perspective of the general public) a rather arcane rule which is unlikely to ameliorate any deterrent effect on testing.

Such a concern has recently formed the basis of an article by Bird and Leigh Brown in the BMJ regarding the Stephen Kelly case. ${ }^{21}$ Bird and Leigh Brown argue that Kelly's conviction is likely to prove damaging to public health. By means of a mathematical model, they suggest that it might risk "a one third increase in new HIV infections in Scotland". The model which they use, however, is arguably seriously flawed. They start from the proposition that the criminalisation of HIV transmission in the Kelly case could have two possible deterrent effects: first, by discouraging HIV testing; second, by encouraging persons who have tested positive for HIV to disclose their HIV-positive status to their sexual partners (or, at least, to use condoms). The first is likely to result in an increase in new HIV infections, the second in a decrease. Bird and Leigh Brown's conclusion is that the "negative" deterrent effect (deterring testing) is likely to substantially outweigh the "positive" deterrent effect (encouraging disclosure or condom use).

That conclusion, however, is necessarily based on a number of assumptions, some of which are open to question. Bird and Leigh Brown assume that prior to the Kelly case, $90 \%$ of knowingly HIV-positive persons would have disclosed their HIV-positive status to their sexual partners and that $70 \%$ of non-disclosers would have used condoms. These assumptions, which are not really consistent with the published literature on self disclosure of HIV status, ${ }^{22}$ minimise the possible consequences of the "positive" deterrent effect in their model. 
Bird and Leigh Brown argue, fairly, that persons who do not know that they are HIV-positive are less likely to use condoms and that a decrease in the uptake of HIV testing would therefore, considered by itself, increase the potential for HIV transmission. However, their assumption (without supporting evidence) that the Kelly case might lead to a $25 \%$ decrease in the uptake of HIV testing (from an assumed uptake of $80 \%$ of HIV-positive persons to $60 \%$ ), is problematic. It is difficult to reconcile this with their earlier assumption that, prior to the Kelly case, $90 \%$ of those HIV-positive persons who did take an HIV test would have thereafter disclosed their HIV status to their partner. To accept their model, therefore, one must accept that a very substantial number of persons who would, prior to the Kelly case, have taken an HIV test and disclosed their HIVpositive status to their sexual partners, will, as a result of the Kelly case, refrain from taking an HIV test. The assumption is that persons will refrain from taking an HIV test in order to avoid being compelled by law to do something which they would have done anyway - which seems rather odd, to say the least.

Although Bird and Leigh Brown raise a valid concern, which certainly warrants further consideration (and the present author would wholeheartedly support their call for "Scotland's health minister to commission the necessary measurements to guide medical and legal decision making"), it might be observed that one could simply adopt their mathematical model, substitute a different set of assumptions as to uptake of HIV testing, rates of disclosure, and condom use, and conclude (for example) that the Kelly case "offers the possibility of a one-third decrease in the number of new HIV infections in Scotland". Their model is certainly useful, but it is not clear that it proves anything.

Bird and Leigh Brown, incidentally, are probably incorrect in their assertion that "the Kelly verdict has criminalised undeclared, but not untested, HIV transmission". Kelly was convicted of the offence of recklessly causing injury to another, which would not appear to necessarily require explicit knowledge of one's HIV-positive status. ${ }^{23}$ To return to the issue of recklessness: even if recklessness is accepted as sufficient to trigger culpability for HIV transmission and/or exposure, this is not to suggest that persons should be required to disclose every last detail of their sexual history to prospective partners. Such a failure (if failure it is) could hardly be held to amount to criminal recklessness. It is not difficult to envisage cases, however, where a failure to warn of a serious risk that a sexual partner is HIV-positive could amount to such recklessness. The possibility of criminalising such behaviour should at least be considered, not ignored, even if it is ultimately rejected. The difficulties involved in defining the standard of recklessness in this context are extensive and have been discussed at length elsewhere. ${ }^{23}$

\section{THE RELEVANCE OF CONSENT}

What if two parties consent to unprotected sexual intercourse, knowing that one is HIV-positive and the other is not? Bennett, Draper, and Frith suggest that, this consent notwithstanding, a criminal offence may have been committed as "English law does not allow a person to consent to the infliction on him/herself of any harm, however grave" (sic). Now that, of course, depends on the question of whether English law actually recognises the transmission of HIV as criminal, which was discussed above. If it does, then the next question is whether a consent to the risk of HIV infection is to be regarded as valid.

However, the issue is not quite so clear cut. English law clearly does recognise consent to harm as valid in a number of circumstances: for example, where the harm is minor, surgical operations, sports, and tattooing, etc. ${ }^{24}$ The authority cited by the authors-the decision of the House of Lords in $R v$ Brown $^{25}$-is concerned with the validity of consent to sadomasochistic acts, and does not support the broad proposition made by the authors.

Indeed, an unsuccessful attempt has already been made to apply the decision in Brown to consent and HIV exposure. In the Canadian case of $R v$ Cuerrier, ${ }^{26}$ the prosecution attempted to argue that, where Cuerrier had engaged in unprotected sexual intercourse with two women without informing them of his HIV-positive status, their consent to intercourse was invalid because of the risk of HIV transmission, and Cuerrier should therefore be regarded as guilty of sexual assault.

The British Columbia Court of Appeal refused to regard the consents as invalid, pointing out that Brown was concerned with consent to injury, whereas a person who consents to unprotected sexual intercourse with an HIV-positive individual consents only to a risk of injury. Secondly, consensual sexual intercourse is seen as serving a "positive social purpose, linking individuals together for pleasure, intimacy, and procreation".

In summary, prior authority would not require the English courts to hold that consent to the risk of HIV infection is to be regarded as invalid, and Cuerrier is persuasive authority which suggests that they would not do so. ${ }^{27}$ That would seem to be the correct approach. Otherwise, a heterosexual couple where only one of the partners is HIV-positive would be committing a criminal offence by attempting to conceive a child, which would seem an abuse of the criminal sanction.

If consent to the risk of HIV infection can be regarded as valid, this may answer one of the other concerns raised by Bennett, Draper, and Frith: specifically, that criminalisation should be limited to cases where it was "reasonable for the partner to assume negativity". In situations where it is not reasonable for the partner to assume negativity, it may be possible to conclude that they have freely consented to the risk of HIV transmission, which would mean that no crime has been committed.

\section{LEVELS OF RISK AND CONDOM USE}

Bennett, Draper, and Frith suggest that a moral duty to disclose should only be recognised where there is a "significant risk of infection"; drawing a distinction between "high" and "low" risk sexual activities. It is important to recognise here that a distinction should be drawn between the moral obligation and any proposed legal obligation. For example, it is clearly arguable that there is a moral duty of disclosure towards a partner with whom an HIV-positive individual has protected sexual intercourse-as condoms probably only reduce the risk of HIV transmission by around $69 \%{ }^{28}$ Equally, a moral duty might be thought to exist even in relationship to "low-risk" sexual activities, given the consequences of HIV infection. (It should be remembered that we are concerned here with a duty to warn of one's HIV-positive status rather than with a duty to avoid engaging in sexual contact. There is no suggestion that persons have any moral obligation to abstain entirely from such activities.)

But there are good reasons not to place persons in such circumstances under legal obligations of disclosure. Failing to draw a distinction between moral and legal obligations in this context (for example, by criminalising both protected and unprotected intercourse) would reduce the non-discloser's incentive to refrain from high-risk activities and to use condoms. As KJM Smith has suggested, a defence of "reasonable precautions" would be a "proper and necessary concession to human nature" ${ }^{29}$ In other words, the existence of a moral duty is a necessary but not a sufficient condition for invoking the criminal sanction. The legal duty should not be as extensive as the moral one.

\section{NOTIONS OF RESPONSIBILITY}

For the sake of completeness, some observations should be made on an objection raised by Bird and Leigh Brown to the 
Kelly verdict. They argue that "[f]ar from protecting the public, [this] judgment has endorsed abrogation of individual responsibility in sexual partnerships by asserting a legal duty of disclosure on the infected partner".

I have responded to this at some length elsewhere, ${ }^{30}$ but it should at least be observed that the notion of responsibility which the authors appear to be applying is fundamentally flawed. It might be an abrogation of responsibility for one's personal safety to walk alone in certain areas during the hours of darkness, but if one were assaulted whilst doing so it would be nonsensical to suggest that to convict the assailant implied an "endorsement" of such abrogation. Equally, it is not inconsistent to view it as irresponsible to hitchhike alone late at night while at the same time being appalled by the actions of the judge who, in 1982, took the view that a woman who was raped in these circumstances was guilty of "contributory negligence", thereby justifying a relatively lenient sentence for her attacker. $^{31}$

Responsibility, as between two parties, is not an either/or concept in the way that Bird and Leigh Brown suggest, and attributing culpability to one party is not the same as saying that the other party bears no responsibility.

\section{CONCLUSION}

While there is a role for the criminal law in restricting the spread of HIV (although some might dispute even that), it is a minor one, and pales into insignificance alongside broader public health measures. Nevertheless, the criminal law does have a role in shaping attitudes and (hopefully) altering behaviour. If specific legislation is to be drafted to address issues of HIV transmission and exposure, the scope of any offence created must be carefully delineated.

The problem which this presents (and it may be a partial explanation for the legislative inactivity thus far in the UK) is the multitude of issues involved and the lack of any obvious answer to any of the many questions which may be raised. This paper has aimed not to provide conclusive answers, but rather to contribute to the debate by focusing the issues.

\section{ACKNOWLEDGMENT}

The author is grateful to the anonymous referees for their helpful comments on an earlier draft of this paper. The usual caveats apply.

\section{REFERENCES}

1 Bennett R, Draper H, Frith L. Ignorance is bliss? HIV and moral duties and legal duties to forewarn. J Med Ethics 2000;26:9-15.
2 Chalmers J. Sexually transmitted diseases and the criminal law. Juridical Review 2001:259-78.

3 Home Office. Violence: reforming the Offences Against the Person Act 1861. London: The Stationery Office, 1998: para 3.18.

4 R v Bennett (1866) 4 F\&F 1105, 176 ER 925; R v Sinclair (1867) 13 Cox CC 28

5 Offences Against the Person Act 1861: s47.

6 R v Clarence (1888) 22 QBD 23, per Stephen J at 41 . Bennett, Draper and Frith refer to the case of Hegarty $\vee$ Shine (1878) 14 Cox CC 145 , but it should be noted that this is a civil case, not a criminal one.

7 R v Ireland; R v Burstow [1998] AC 147.

8 Anonymous. The deadly legacy of my husband's ex. Cosmopolitan [British ed]. 2001 Jun:63-4.

9 UNAIDS. Handbook for legislators on HIV/AIDS, law and human rights. Geneva: UNAIDS, 1999: 51

10 R v Wentzell (Scott), 8/12/89, county court of Nova Scotia, CR no 10888 , unreported.

11 R v Cuerrier (1996) 141 DLR (4th) 503, per Prowse JA at 526

12 R v R, York Crown Court, June 1998, unreported.

13 R v Sullivan, Horseferry Road Magistrates' court, 11 January 2002, unreported.

14 Smith KJM. Sexual etiquette, public interest and the criminal law. Northern Ireland Legal Quarterly 1991;42:309-31, at 324

15 See generally Ashworth A. Belief, intent, and criminal liability. In: Eekelaar J, Bell J, eds. Oxford essays in jurisprudence 3rd series. 1987: 1-31, at 16-20; Kadish SH. The criminal law and the luck of the draw. Journal of Criminal Law and Criminology 1994;84:679-702.

16 Duff RA. Criminal attempts. Oxford: Clarendon Press, 1996: 328-34

17 Smith JC. The element of chance in criminal liability. Criminal Law Review 1971:63-75, at 73.

18 R v Cuerrier [1998] 2 SCR 371

19 Criminal Attempts Act 1981: s1

20 Ashworth A. Principles of criminal law [3rd ed]. Oxford: Oxford University Press, 1999: 196-7.

21 Bird SM, Leigh Brown AJ. Criminalisation of HIV transmission: implications for public health in Scotland. BM 2001;323:1 174-7. Electronic responses to this article by the present author and others can be found on the BM website: <http://bmi.com/cgi/eletters/323/ 7322/1174>

22 See primarily Stein MD, Freedberg KA, Sullivan LM, et al. Sexual ethics: disclosure of HIV-positive status to partners. Arch Intern Med 1998;158:253-257; Marks G, Richardson JL, Maldonado N Self-disclosure of HIV infection to sexual partners. Am J Public Health 1991:81:1321-2.

23 Tadros V. Recklessness, consent and the transmission of HIV. Edinburgh Law Review 2000;5:371-80.

24 See reference 20: 330-7.

25 [1994] 1 AC 212.

26 (1996) 141 DLR. (4th) 503. An appeal to the Supreme Court of Canada was allowed on other grounds: [1998] 2 SCR 371

27 Although see the US case of US v Bygrave 46 M 491 (1997).

28 Weller SC. A meta-analysis of condom effectiveness in reducing sexually transmitted HIV. Social Science and Medicine 1993;36:1635-44.

29 See reference 12: 328

30 Chalmers J. Criminalisation of HIV transmission: a reply. BM online, 17 November 2001. <http://www.bmj.com/cgi/eletters/323/7322/ $1174 \#$ EL 1>

31 Patullo P. Judging women. London: National Council for Civil Liberties, 1983: 21-3. It should be noted that, on the particular facts of this case, where the victim had been left with little option (if any) but to hitchhike, it was almost certainly unfair to accuse her of irresponsibility. 